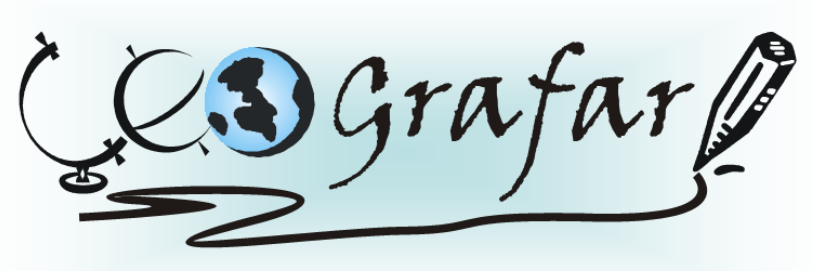

Revista Eletrônica do Programa de Pós-Graduação em Geografia - UFPR

\title{
SEGREGAÇÃO SÓCIOESPACIAL E O PODER PÚBLICO - UMA ANÁLISE DO PROJETO DE DESFAVELAMENTO EM SOROCABA-SP
}

\section{SPATIAL SEGREGATION AND PUBLIC AUTHORITIES - AN ANALYSIS ABOUT THE PROJECT OF REVIVAL FOR SLUMS IN SOROCABA - SP}

\author{
(Recebido em 22.07.2012; Aceito em 06.02.2013) \\ Felipe Comitre \\ Mestrando em Geografia, Organização do Espaço - UNESP Rio Claro \\ Rio Claro, SP, Brasil \\ e-mail: felipe.comitre@hotmail.com
}

Silvia Aparecida Guarnieri Ortigoza

Prof $^{a}{ }^{-a}{ }^{\underline{a}}$ do Departamento de Geografia - UNESP Rio Claro

Rio Claro, SP, Brasil

sago@rc.unesp.br

\begin{abstract}
Resumo
Este artigo é fundamentado na caracterização do processo de segregação sócioespacial nas cidades brasileiras, partindo da análise da atuação do poder público no aumento e geração deste problema urbano. Demonstrando, deste modo, como este processo interfere na dinâmica existente na estrutura urbana, assim como na reprodução das relações sociais nas cidades. Tendo como base para esta argumentação, o estudo de caso do Projeto de Desfavelamento em Sorocaba. A análise deste, parte, inicialmente, da realização de um breve histórico sobre o processo de favelização no município de Sorocaba e, posteriormente, questiona-se como esta ação do poder público, que resultou na construção do Conjunto Habitacional Ana Paula Eleutério, foi responsável por estimular o processo de segregação sócioespacial na cidade. Abordando, assim, suas consequências para a sociedade em conjunto com o espaço urbano e, discutindo, as reais intenções existentes com algumas políticas públicas, especialmente, as relacionadas com a fomentação da segregação sócioespacial no espaço urbano.
\end{abstract}


Palavras-Chave: segregação sócioespacial; projeto de desfavelamento; estrutura urbana.

\begin{abstract}
This article is based on the characterization of the segregation in brazilian cities, analyzing the performance of the government and the increased generation of urban problem. Showing thus how this process interferes with the dynamics existing in the urban structure, as well as the reproduction of social relations in cities. Taking as a basis for this argument, the case study project of the non-urban slum in Sorocaba. The analysis of this part, initially carrying out a brief history of the process of slums in the city of Sorocaba and then wonders how this action of the government, resulting in the creation of the assembly housing Ana Paula Eleutério, was responsible to stimulate the process of segregation in the city. Approaching thus its consequences for society in conjunction with the urban space, and discussing the real intentions with some existing public policies, especially those related to the fostering of segregation in urban space.
\end{abstract}

Keywords: sociospatial segregation; proposed end slums; urban structure.

\title{
Introdução
}

Ao analisar o processo de segregação sócioespacial nas cidades capitalistas, torna-se fundamental apresentar como ponto de partida o espaço urbano, como produto, meio e condição das relações sociais (CARLOS, 2004). Deste modo, entende-se que as relações sociais se materializam no espaço e, por outro lado, as formas já existentes no território interferem na reprodução da sociedade. Portanto, são nas cidades capitalistas que se presenciam e concretizam as desigualdades sociais inerentes a este modo de produção. Gerando assim, uma cidade fragmentada em que cada parte do território possui determinadas características, fato este que Corrêa (2001) define pela justaposição de diferentes paisagens e usos da terra.

Neste contexto, cada parte da cidade possui potencialidades e fragilidades quanto a serviços e equipamentos urbanos de uso coletivo e, conseqüentemente, estas diferenças afetam no valor de troca destas áreas, isto é, cada "pedaço" do 
território possui um valor que está relacionado com sua qualidade e quantidade em infraestrutura e serviços. Sendo que a formação deste território heterogêneo está totalmente vinculada à ação dos agentes modeladores do espaço, representados, principalmente, pelos promotores imobiliários, proprietários fundiários e dos meios de produção, o Estado, além dos grupos sociais excluídos, responsáveis pela produção e consumo do espaço urbano.

Assim, o presente artigo tem o intuito de questionar a atuação do poder público na dinâmica da estrutura urbana, demonstrando como este agente pode estimular na produção de um espaço segregado e controlado, no qual o uso e ocupação do solo vinculam-se cada vez mais ao poder aquisitivo da sociedade. Visando comprovar tal análise, utilizou-se como estudo de caso o Projeto de Desfavelamento de Sorocaba, realizado pela prefeitura municipal no ano de 1997, que foi responsável pelo deslocamento de favelas espalhadas pelo território para um conjunto habitacional localizado em uma área periférica. Este artigo é resultado de um trabalho de conclusão de curso, realizado em 2010, sendo que o estudo de caso foi analisado por meio de um levantamento bibliográfico sobre o tema referente à produção do espaço urbano, utilizando-se de autores de destaque nesta área, além disso, foram realizados trabalhos de campo, com o intuito de melhor compreender o contexto local, juntamente com a utilização de dados estatísticos, notícias de jornais e também da análise dos materiais existente do acervo da Prefeitura Municipal de Sorocaba.

Destaca-se nesta pesquisa, a importância da Geografia como uma ciência social que ressalta ao longo da história de seu pensamento científico a análise das questões urbanas, tendo como fundamento para este artigo, as transformações na estrutura urbana e suas conseqüências para a reprodução das relações sociais.

\section{Caracterização da área de estudo}

O município de Sorocaba se localiza no sudoeste do estado de São Paulo, distanciando-se, aproximadamente, 95 quilômetros da capital. Já em relação ao 
aspecto populacional, Sorocaba conta, atualmente, com 586.311 mil habitantes (CENSO, 2010).

Para promover um embasamento mais adequado sobre o processo de desenvolvimento e urbanização em Sorocaba e, consequentemente, realizar uma análise detalhada e crítica sobre a estrutura urbana deste município, torna-se fundamental contextualizar, inicialmente, a importância da cidade na produção agrícola, especialmente, de dois produtos: o algodão e o café. Isto porque tais produções estimularam a construção da Estrada de Ferro Sorocabana, em 1875, sendo que esta visava, sobretudo, contribuir na consolidação da exportação destes produtos para outras cidades, conferindo assim, uma importância do município para o contexto regional do estado.

No decorrer do desenvolvimento de Sorocaba, após a construção da ferrovia, percebe-se durante o século $X X$, a gênese de sua industrialização, pautada, primeiramente, na indústria têxtil e, posteriormente, na fixação de indústrias de bens de consumo em seu território. Portanto, foi neste momento que se efetivou o início da urbanização na cidade, além de seu crescimento econômico. Entretanto, como foi demonstrado anteriormente por meio da construção da Estrada de Ferro Sorocabana, a industrialização de Sorocaba obteve determinado sucesso devido à construção de dois eixos rodoviários que permitiram o escoamento destes produtos, então, a construção da rodovia Raposo Tavares (SP 270), em 1954, e a Castelo Branco (SP 280), em 1967, favoreceram a formação de trajetos que permitiram um maior deslocamento de mercadorias e pessoas entre a cidade com as demais, especialmente com a capital do estado. Vale destacar que esta política de construção de rodovias estava em ascensão na época, permitindo a integração de várias regiões do país, como explica Santos (1994, p. 39) que "a partir de 1960 , constroem-se estradas de rodagem de primeira ordem. O Brasil passa a ser cruzado por um grande número de rodovias de boa qualidade, entre as quais um bom percentual de autopistas".

A convergência entre industrialização e integração na cidade foi responsável por atrair um significativo contingente populacional para Sorocaba, geralmente, migrantes em busca de trabalho e melhores condições de vida. Desta forma, o processo de urbanização adquire ascensão considerável no município 
simultaneamente ao crescimento de sua população urbana, já que a população das áreas rurais, de outras localidades próximas, assim como as oriundas de outras regiões e estados passaram a se fixar na cidade de Sorocaba, promovendo o inchaço populacional da mesma. Segundo os dados do IBGE (CENSO 2000), 19\% da população de Sorocaba eram nascidas em outros estados, destacando os paranaenses com 38,6 mil e os mineiros com 12 mil, além dos oriundos dos estados do nordeste totalizando 33 mil habitantes. Este alto índice de crescimento populacional aliado à degradação da classe trabalhadora nas cidades capitalistas, resultou na eclosão de inúmeros problemas urbanos em Sorocaba. Merecendo destaque o habitacional, no qual a conjuntura má remuneração dos trabalhadores e falta de políticas habitacionais de interesse social acarretou na falta de moradia para grande parcela da população na cidade, fomentando, assim, o processo de favelização no município.

Ao analisar a problemática da moradia nas cidades, Kowarick (1983) esclarece que além da compressão salarial, o aumento expressivo do preço da terra urbana que também atuou nas áreas periféricas, contribuiu para o agravamento do acesso a casa própria. Como conseqüência destes fenômenos, a população que não conquistava o acesso à moradia de forma legal passou a ocupar áreas irregulares da cidade, contribuindo com a formação de favelas em seu território. Assim, "o processo de urbanização se apresenta como uma máquina de produzir favelas e agredir o meio ambiente" (MARICATO, 2002, p. 39).

A situação específica do município de Sorocaba foi descrita por Zimmermann, da seguinte maneira:

A favelização (em Sorocaba) ganhou sua dimensão numérica, segundo a Secretaria Municipal de promoção Social, apenas no final dos anos 70 e início dos 80 , quando atingiu cerca de $2 \%$ da população urbana. (ZIMMERMANN, 1992, citado por MEIRA, 2006, p. 69)

A Prefeitura Municipal de Sorocaba reconhecendo esta forma de apropriação do espaço urbano para moradia, que vinha afetando consideravelmente na estrutura urbana da cidade devido ao crescimento de favelas e ocupações irregulares, realizou por meio da Secretaria de Cidadania do Município em conjunto com o Fundo Social de Solidariedade, o Projeto de Desfavelamento de Sorocaba. Este 
projeto foi iniciado em 1997, e consistiu basicamente na retirada de aproximadamente 500 famílias localizadas em favelas e áreas de risco distribuídas pela cidade, tendo como objetivo remanejar esta população para lotes urbanizados, visando, enfim, melhorar as condições de vida da população por ele beneficiada.

Como produto desta ação foi terminado em julho de 1998, a construção do Conjunto Habitacional Ana Paula Eleutério, denominado popularmente de Habiteto. Localizado em uma área periférica nas margens da Avenida Itavuvu, na Zona Norte da cidade, região esta que é considerada a mais populosa e a que apresenta os piores índices de rendimento do município.

Segundo a Secretaria de Cidadania (SECID, 1997, citado por MEIRA, 2006, p. 69), "o desfavelamento, desenvolvido com o Projeto Habiteto, representa o direito de ter uma vida digna, ou seja, representa o direito à cidadania às pessoas que deles serão beneficiadas". Para ser beneficiada com um lote pelo Projeto de Desfavelamento, a população necessitava estar instalada na cidade há mais de três anos em áreas de ocupação irregular e consideradas de risco, além de não possuir nenhum imóvel. Sendo que "cada lote custa mil e setecentos reais, e o assentado paga de acordo com sua condição financeira" (DESFAVELAMENTO, 2003, citado por MEIRA, 2005, p. 103).

O projeto inicial previa a construção das moradias para os beneficiados por meio da ação em conjunto com a Companhia de Desenvolvimento Habitacional e Urbano (CDHU), porém, esta não concordou com a área cedida pela prefeitura por considerar fora dos padrões estabelecidos pelo projeto, alertando a distância do assentamento em relação ao centro, responsável por gerar pouca viabilidade de inclusão com o restante da cidade, além do difícil acesso ao centro comercial e aos empregos, causando a exclusão social desta população.

Os serviços urbanos se irradiam do centro à periferia, tornando-se cada vez mais escassos à medida que a distância do centro aumenta. Além disso, o conjunto da população e das empresas utilizam, em alguma medida, os serviços disponíveis apenas no centro principal, de modo que a distância em que se encontram do referido centro determina seus gastos de transporte (em dinheiro e em tempo) cada vez que se deslocam até ele. (SINGER, 1982, p. 29) 
A Figura 1 demonstra a localização do conjunto habitacional em relação ao centro, deve-se enfatizar que a distância entre estes pontos é de aproximadamente onze quilômetros.

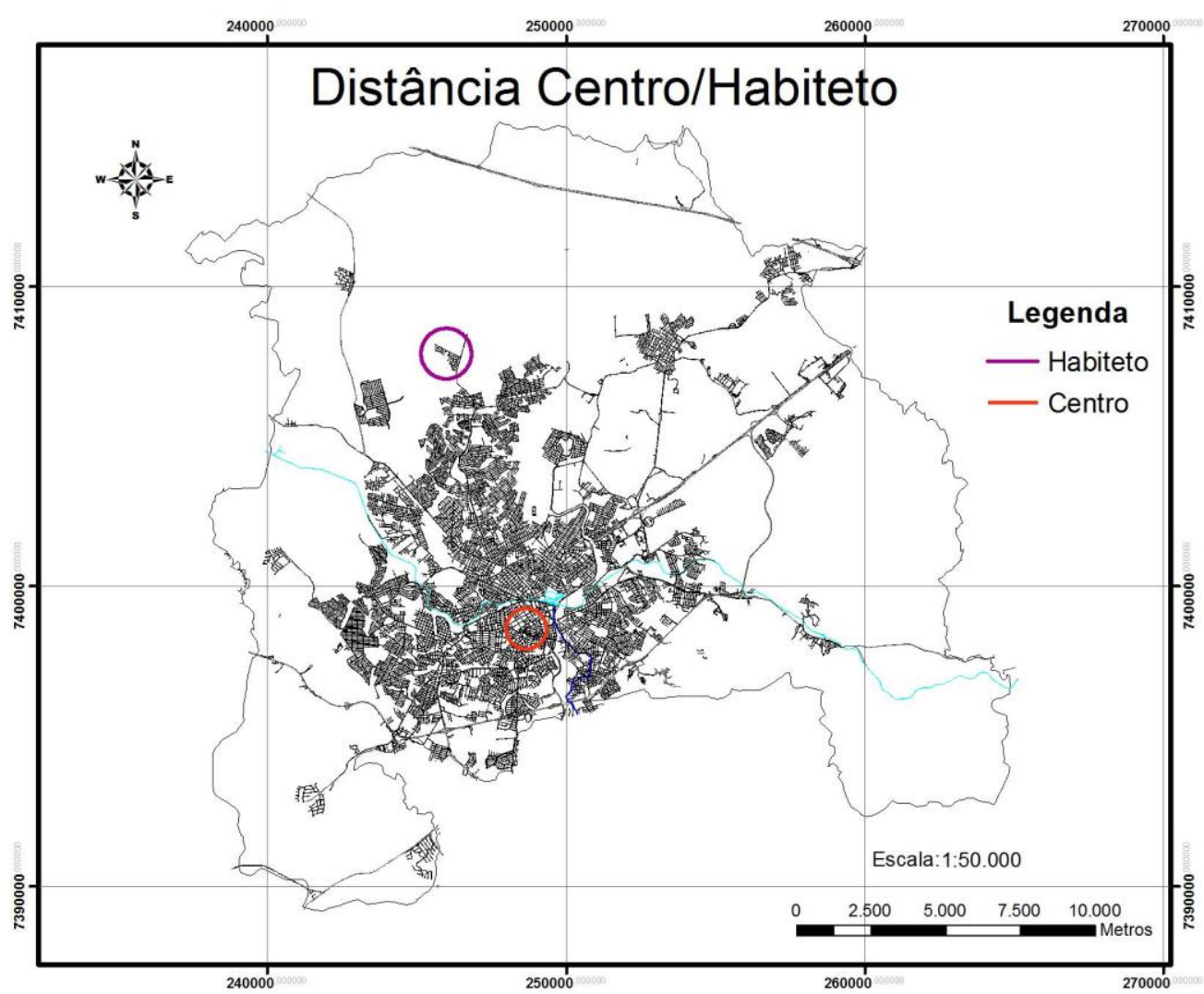

FIGURA 1 - Localização do Habiteto em relação ao centro.

Fonte: Plano Diretor 2005.

Elaborado por Felipe Comitre.

Contudo, ocorreu uma significativa falta de planejamento para a execução do Projeto de Desfavelamento, pois a população das favelas e das áreas irregulares do município já havia sido transferida para os lotes fornecidos pela prefeitura antes mesmo da decisão dos técnicos da CDHU. Porém, como já foi elucidado anteriormente, a companhia não concordou com a área e não construiu as casas e, mesmo assim, a prefeitura de Sorocaba não realizou as obras por conta própria, nem executou um novo remanejamento desta população.

Sendo assim, a ação da Prefeitura de Sorocaba se caracterizou pelo caráter de inibir novas ocupações em áreas irregulares nas cidades, isto porque, a medida adotada pelo poder público foi de remover a população favelada que se encontrava 
distribuída pela cidade, bem como de promover constantes ameaças de remoção nas ainda ocupadas.

Esta atuação do poder público também pode ser elucidada visando atender as exigências dos agentes modeladores do espaço nestas áreas, ocasionando a sua valorização, principalmente, por meio de uma política de higienização do território que confere uma preocupação exacerbada com a imagem em detrimento do social. Carlos (2001, p. 27) explica como o poder público provoca significativa interferência no valor de troca do espaço urbano ao afirmar que:

\begin{abstract}
O Estado, com seus instrumentos legais, produz grandes transformações nos usos e funções dos lugares da cidade, reproduzindo a hierarquia desses lugares no conjunto do espaço metropolitano. Mas, ao direcionar-se os investimentos em infra-estrutura, aprofundam-se as desigualdades na metrópole, interferindo de modo profundo nas formas de apropriação do espaço à medida que produzem, com sua intervenção, um processo de valorização diferencial do solo urbano.
\end{abstract}

No caso analisado, percebeu a atuação do Estado em inibir uma forma de uso do solo urbano, isto é, a presença de favelas. Por outro lado, foi demonstrado que ao estimular o crescimento periférico da cidade, a prefeitura de Sorocaba conferiu uma distribuição desigual dos equipamentos urbanos por seu território. Tornando-se notável os interesses envolvidos com este projeto, que foram favoráveis exclusivamente ao mercado imobiliário, assim como para a população de maior poder aquisitivo que com a ação do poder público, não precisou mais conviver com as favelas e seus habitantes.

[...] a favela torna-se um problema na medida em que, com a expansão da cidade, a área que ocupa começa a se valorizar. Ou são as vias expressas e prédios públicos que reclamam o espaço tomado pelos barracos - e é preciso removê-los. Ou é a lógica da especulação imobiliária que leva o investidor privado a tomar a iniciativa da operação "limpeza" - e como a fonte última do direito é a propriedade, o favelado junta seus trastes e vai se instalar em outro lugar, até que o crescimento da metrópole que ele ajuda a contribuir o expulse novamente. (KOWARICK, 1983, p. 160)

Então, a prefeitura manteve a população "beneficiada" nestes lotes, mas também não construiu as moradias previstas pelo projeto, ocorrendo, assim, praticamente uma transferência do local das favelas no território, já que a construção de moradias improvisadas foi predominante no novo assentamento. Em muitos 
casos, os moradores retiraram as madeiras e outros materiais de seu barraco antigo e transferiram para os lotes que foram providos pela prefeitura. Santos (1994, p. 112), alerta que "o poder público, entretanto, não age apenas de forma indireta. Ele também atua de forma direta na geração de problemas urbanos, ainda que prometendo resolvê-los".

Os únicos benefícios relacionados à infraestrutura promovidos inicialmente pela prefeitura no Conjunto Habiteto foram o de serviço de água e esgoto e de energia elétrica, realizados em parceria respectivamente com o SAAE (Serviço Autônomo de Água e Esgoto de Sorocaba) e com a CPFL (Companhia Piratininga de Força e Luz). Já a pavimentação asfáltica que foi prometida no projeto inicial foi realizada apenas em 2004, isto é, seis anos após os moradores se instalarem no assentamento, mostrando o descaso do poder público com os moradores do Habiteto.

Ao analisar o Projeto de Desfavelamento de Sorocaba, torna-se visível sua função em prol da elite socioeconômica e do mercado imobiliário em detrimento do bem estar social na cidade. Sendo que este projeto estimulou a segregação sócioespacial na cidade, isto é, caracterizou por delimitar o local de cada habitante na apropriação do espaço urbano, tendo como base para esta ocupação o poder aquisitivo da sociedade.

\section{O processo de segregação sócioespacial nas cidades capitalistas}

A análise da organização espacial das cidades, partindo da distribuição da população em seu território de acordo com os diferentes modos de apropriação do espaço urbano, pode ser evidenciada nas metrópoles, bem como nas cidades médias, a partir do reconhecimento do processo de segregação sócioespacial, entendido como "um processo segundo o qual diferentes classes ou camadas sociais tendem a se concentrar cada vez mais em diferentes regiões gerais ou conjuntos de bairros." (VILLAÇA, 2001, p. 142), sendo responsável por interferir significativamente na estrutura urbana. 
Para analisar a estrutura urbana torna-se necessário compreender o processo de produção do espaço, que se fundamenta como condição, meio e produto das relações sociais (CARLOS, 2004), podendo assim, entender a dinâmica na qual a sociedade no ato produzir sua vida cotidiana simultaneamente (re)produz o espaço.

Tendo este conceito em mente, deve-se destacar que as relações sociais atualmente são pautadas no modo de produção capitalista, este por sua vez, atua na produção do espaço como uma mercadoria. Pois, o espaço urbano é fragmentado em partes que são vendidas por meio das propriedades privadas. "Deste modo, o espaço entra no circuito da troca, generalizando-se na sua dimensão de mercadoria" (CARLOS, 2004, p. 91).

Neste âmbito, os agentes modeladores do espaço atuam segundo a lógica do capital, acarretando na produção de um espaço heterogêneo. Então, a estrutura urbana torna-se fragmentada, caracterizada pela justaposição de diferentes paisagens e usos do solo (CORRÊA, 2001). Diferenças visíveis, sobretudo, pela distribuição dos bens e serviços pela cidade, que não são produzidos homogeneamente em seu território.

A diferenciação das áreas, quanto aos equipamentos urbanos necessários à reprodução da vida, causa a distinção de classes em setores na estrutura urbana, isto é, a distribuição da população no espaço urbano se pauta pelo seu poder aquisitivo, que lhe permite ou não apropriar-se de determinadas áreas.

A rigor, os equipamentos coletivos deveriam beneficiar todos os moradores das cidades. Porém verifica-se que para serem utilizados é necessária uma capacidade de pagar que depende do lugar que os moradores ocupam no interior da divisão do trabalho, o que define seu lugar na cidade. (RODRIGUES, 1988, p. 51 e 52)

Cria-se assim, a disputa entre classes no espaço intraurbano, disputa essa regulada pelas vantagens e desvantagens existentes no território. Segundo Villaça (2001, p. 330), "a luta pela localização entre as classes sociais é uma luta em torno de condições de consumo, não em torno de condições de produção".

Contudo, é a classe mais abastada que se segrega nas áreas mais privilegiadas, buscando atender suas necessidades de consumo, restando à população com menores recursos financeiros fixarem em áreas que não atraem os interesses das demais. Logo, a escolha pela apropriação das diferentes partes do 
espaço é ditada pela classe com maior poder aquisitivo, sendo que a segregação desta classe gera simultaneamente a segregação das demais classes, considerando a segregação sócioespacial, então, um fenômeno dialético. Como explica Villaça (2001, p. 147 - 148) ao afirmar que na "verdade, não há dois tipos de segregação, mas um só. A segregação é um processo dialético, em que a segregação de uns provoca, ao mesmo tempo e pelo mesmo processo, a segregação de outros".

O processo de segregação sócioespacial resulta, portanto, na fragmentação da cidade em partes menores, sendo que cada uma delas possuem seu preço, correspondente ao consumo do lugar. Desta forma a população vai apropriar-se destas parcelas do território, atrativas ou não, de acordo com a sua função desempenhada nas relações de produção. Rodrigues (1988, p. 32) complementa esta ideia explicando que "a cidade capitalista confere a cada um o "seu lugar" visto que a configuração do urbano tende a reproduzir as classes do capitalismo".

É dentro deste contexto que se caracteriza a estrutura urbana da cidade de Sorocaba, pois a forma de residir da população encontra-se dividida em bairros que concentram determinada classe social. Isto é, as áreas com melhores equipamentos urbanos são habitadas, em sua maioria, pela classe de maior renda, em contrapartida, cabe à população de baixa renda se fixar em áreas que apresentam déficit em relação aos bens e serviços da cidade, fundamentalmente devido às diferenças existentes quanto aos valores da terra. Portanto, na cidade capitalista qualquer forma de apropriação de terra apresenta-se vinculada ao seu pagamento. Por sua vez, o direito de residir próximo aos equipamentos urbanos de consumo coletivo também se torna possível mediante sua compra.

Segundo Harvey (1980):

[...] o solo e as benfeitorias são, na economia capitalista contemporânea, mercadorias. Mas o solo e as benfeitorias não são mercadorias quaisquer: assim, os conceitos de valor de uso e de troca assumem significado mais que especial. (p. 135)

Ao avaliar o processo de segregação sócioespacial, torna-se perceptível a ausência de capacidade de ação da população de menor renda em transformar esta realidade. Pois o mercado imobiliário e o modo de produção vigente convergem para a degradação de sua classe, isto porque ela está sujeita a aceitar passivamente a 
apropriação das melhores áreas do território urbano pela classe mais abastada, não tendo sequer o poder de competir por esses espaços, já os mesmos possuem valores que impedem sua apropriação. Sendo que, "o funcionamento do mercado imobiliário faz com que a ocupação destas áreas seja privilégio das camadas de renda mais elevada, capaz de pagar um preço alto pelo direito de morar" (SINGER, 1982, p. 27).

A população pobre, portanto, deve se contentar em habitar as áreas relegadas pelas classes de melhores recursos financeiros, assim como pelas que não interessaram ao mercado imobiliário. Estando localizadas, especialmente, nas periferias da cidade, distantes dos centros econômicos e históricos, nas quais elas devem viver com a contínua falta de equipamentos necessários à realização da vida. Dando significado a periferia às áreas que apresentam escassez de serviços e bens, e não as periferias elitizadas, dotadas de inúmeros equipamentos, que são produzidas atualmente para atender as necessidades de consumo da classe de alta renda.

Rodrigues (1988) faz uma breve elucidação sobre a situação da infraestrutura e serviços na periferia, defendendo que:

\footnotetext{
Basta ir até a "periferia" para verificar que os produtos têm qualidade inferior e custam muito mais caro. Não podem ter "direitos", já que foi definido que não "deveriam" ter acesso à propriedade e que seu salário deveria ser apenas "suficiente" para a sua sobrevivência imediata. Não podem, porque a cidade é produzida socialmente, mas a renda é apropriada individualmente. (p. 84)
}

Compreendendo este processo inerente a configuração das cidades capitalistas, questiona-se o papel que o Estado deve desempenhar visando atenuar tal problema, como desenvolver a integração entre as partes fragmentadas da cidade. Entretanto, infelizmente, ao avaliar as medidas por ele realizadas, evidenciam-se ações que não somente mantém este problema urbano, como também o estimula. Como o exemplo do Projeto de Desfavelamento da Prefeitura de Sorocaba, responsável por segregar ainda mais os seus "beneficiados", que se encontravam espalhados em favelas e áreas de risco pela cidade, mas que se localizavam próximo ao centro de serviços e, após a atuação do poder público, 
foram transferidos para uma área distante dos principais serviços e precária quanto às condições de infraestrutura.

A Figura 2 demonstra a estrutura urbana da cidade de Sorocaba, delimitando também o Habiteto, de acordo com a distribuição da população pelo território, tendo como referencial desta espacialização, o rendimento dos chefes de família. Deste modo, o mapa vai demonstrar a partir dos dados estatísticos do IBGE, a fragmentação do município em partes que concentram determinada classe social, comprovando, portanto, a segregação sócioespacial na cidade.

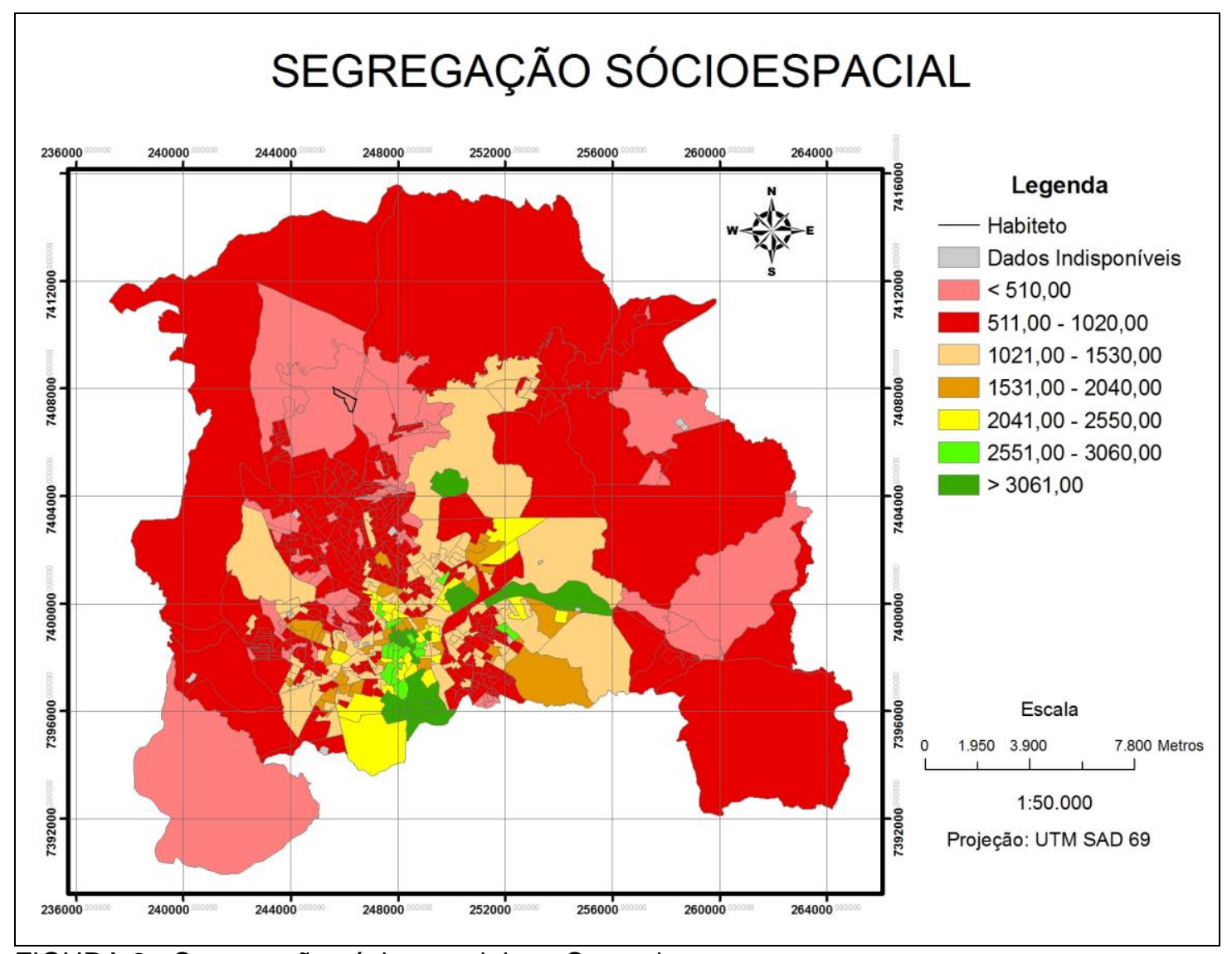

FIGURA 2 - Segregação sócioespacial em Sorocaba.

Fonte: Plano Diretor 2005/Censo Demográfico 2000.

Elaborado por: Eder Roberto Silvestre/Felipe Comitre.

Ao analisar o mapa juntamente com o contexto já apresentado sobre a criação do Conjunto Habitacional Habiteto, evidencia-se que o projeto da prefeitura, ao remanejar a população espalhada pela cidade para uma área periférica, contribuiu para fomentar a segregação, bem como a degradação da vida da população por ele "beneficiada", já que os equipamentos urbanos básicos não foram 
desenvolvidos previamente no local. Caracterizando-se, portanto, como uma política que impede aos pobres habitar as mesmas áreas que os ricos.

Para Engels (1975, p. 47):

\begin{abstract}
Todas as grandes cidades têm um ou vários bairros pobres onde se concentra a classe operária. É certo que muitas vezes a pobreza habita tugúrios escondidos perto dos palácios dos ricos; mas, de uma maneira geral, é lhe atribuído um terreno à parte, longe das vistas das classes mais felizes, onde o proletariado se governa sozinho, bem ou mal. Estes bairros miseráveis são organizados da mesma forma em quase toda a Inglaterra e constituídos pelas piores casas, nas zonas piores da cidade.
\end{abstract}

A realidade de Sorocaba, portanto, não se difere das cidades inglesas apresentadas por Engels no período posterior a Revolução Industrial. O mapa elucida a divisão da cidade em setores que concentram a população de acordo com seu poder aquisitivo, enfatizando a região localizada ao sul de Sorocaba com os melhores índices de rendimento, em detrimento da região Norte, que apresenta os piores níveis de renda.

Ao delimitar o Conjunto Habitacional Habiteto no mapa de Sorocaba, comprovou-se que a sua localização converge com os piores índices de rendimento dos chefes de família da cidade, consistindo em uma renda inferior a um salário mínimo (equivalente a 510 reais em 2010). Sendo assim, deve-se considerar que além da divisão do trabalho existente no modo de produção atual, as ações públicas realizadas por meio de suas políticas sociais também interferem na distribuição da população nas cidades. Fato este que solidifica a presença do fenômeno de segregação sócioespacial nos centros urbanos brasileiros.

\title{
A segregação sócioespacial como forma de controle do espaço urbano
}

Foi visto até o presente momento que o processo de segregação sócioespacial se pauta na disputa entre classes pela localização das áreas de melhores atrativos, tanto naturais como de equipamentos urbanos, que culminam na concentração de classes em setores urbanos. Entretanto, este processo necessita ser mais bem estudado para compreendê-lo em sua plenitude, deste modo, Villaça (2001) elucida que devem ser realizados dois avanços para alcançar esta meta. 
Sendo o primeiro incluir o controle do tempo de deslocamento como dos principais objetivos da produção do espaço urbano, e o segundo em entender as razões profundas da segregação, suas enormes implicações econômicas, políticas e ideológicas.

Neste contexto, o controle do tempo de deslocamento nos fluxos diários é um fator essencial para entender a dinâmica da segregação, pois a população tende a priorizar a apropriação de áreas que apresentem articulação com as demais, com a finalidade de facilitar suas relações cotidianas, como acesso ao emprego, aos centros comerciais e históricos, isto é, aos equipamentos necessários à reprodução da vida. Fator este que esclarece os motivos, antigamente, para a apropriação das zonas centrais pela classe de melhor poder aquisitivo, pois estas áreas eram as que apresentavam as principais vias de acessos da cidade. Entretanto, nas últimas décadas parte desta população vem se transferido para as áreas mais distantes do centro, mas que também apresentam uma rede de equipamentos que permitem a otimização em seu deslocamento diário. Portanto, não é aceitável, hoje em dia, conceituar o fenômeno de segregação sócioespacial meramente como a diferenciação entre centro e periferia. (VILLAÇA, 2001)

O avanço na infraestrutura de transporte que culmina em uma maior integração do território permite que a população mais abastada abandone o centro e se aproprie de áreas mais distantes, contudo, esta transferência se concretiza pelo acesso dos serviços urbanos de qualidade, permitindo, deste modo, a articulação entre as partes fragmentadas da cidade, ocorrendo, neste caso, à integração desta população com o restante da cidade.

Como esclarece Villaça (2001), ao defender que:

\begin{abstract}
Em muitos casos, as camadas de mais alta renda se afastam de seus centros para ocupar bairros mais modernos e espaçosos e com mais verde; entretanto, compensam esse afastamento com vias expressa, auto-estradas e altas taxas de motorização. Ademais, trazem para sua direção de deslocamento o centro da cidade, os empregos e os serviços, os shopping centers, os aparelhos do Estado e os centros empresariais. Com isso, otimizam seus tempos gastos em deslocamento. (p. 343)
\end{abstract}

Torna-se evidente, portanto, que a partir do momento em que a população de maior poder aquisitivo se afasta das regiões centrais, carrega consigo os principais 
equipamentos urbanos, representados especialmente pelos que permitem facilidades em seu deslocamento diário, bem como os que atendam sua necessidade de consumo. Fato este inexistente quando analisado os casos que envolvem a classe trabalhadora, como foi exposto no remanejamento da população de Sorocaba, por meio do Projeto de Desfavelamento que resultou na criação do Conjunto Habitacional Habiteto.

Ao entender esta situação, torna-se necessário examinar os problemas advindos com este processo de segregação sócioespacial aliado a falta de equipamentos urbanos essenciais para a reprodução das relações cotidianas. Dentre os principais problemas, a classe trabalhadora segregada em áreas periféricas, devido à crescente distância, apresenta maiores gastos com 0 deslocamento diário necessário para o acesso ao emprego, assim como aos serviços existentes, sobretudo, no centro comercial e/ou histórico. Como também maior tempo despendido na realização destas tarefas, ocasionados justamente pela distância existente entre sua residência e os serviços urbanos, além da falta de transportes coletivos satisfatórios que atendam esta população.

Sendo assim, a população que habita as áreas periféricas carentes quanto à infraestrutura são relegadas do direito à cidade, já que não podem conviver com a presença dos equipamentos urbanos de uso coletivos necessários à reprodução da vida nas cidades. Segundo Lefebvre (2001), "o direito à cidade não pode ser concebido como um simples direito de visita ou de retorno às cidades tradicionais. Só pode ser formulado como direito à vida urbana, transformada, renovada" (p. 117 e 118).

Conhecendo estas conseqüências, Villaça (2001) ressalta que o real sentido da segregação vem sendo ignorado nas análises espaciais urbanas, defendendo que o principal motivo impulsionador da divisão em setores no espaço urbano é o de controle da burguesia sobre o Estado e sobre o mercado, permitindo a esta classe reivindicar por melhores condições quanto aos equipamentos urbanos por eles fornecidos. Controle este que seria inviável caso esta classe se encontrasse distribuída por todo território urbano.

A segregação por setores possibilita - como nos casos de nossas metrópoles - um sistema viário mais adequado às necessidades dessas 
classes. Além disso, essa alternativa oferece melhores possibilidades de atendimento das burguesias por parte de subcentros ou shopping centers voltados para elas. Nenhuma outra forma de organização espacial atenderia melhor as camadas de mais alta renda do que essa, fosse pelo mercado, fosse pelo Estado. (VILLAÇA, 2001, p. 340)

Esta perspectiva é fundamental para entender a dinâmica do processo de segregação sócioespacial, pois permite compreender as razões que atuam além da disputa entre classes pela apropriação de determinadas áreas. Demonstrando o pretexto empenhado pela classe de renda alta, ao justificar a necessidade de dividir a estrutura urbana em setores moldados através do poder aquisitivo da população.

Isto ocorre, principalmente, porque os equipamentos urbanos são produzidos de forma heterogênea pela cidade, sendo o processo de segregação em setores uma forma adotada pela classe de melhor renda para conseguir obter tais serviços e infraestrutura, mantendo para si as melhores condições presentes no espaço urbano.

Este fator é fundamental para análise da segregação sócioespacial nas cidades brasileiras, pois as classes de maior poder aquisitivo definem locais em comum para habitarem visando, sobretudo, a perpetuação de seu poder no espaço urbano. Já que é esta classe social que possui maior representatividade frente ao poder público, sendo assim, ao se unirem espacialmente adquirem, simultaneamente, força política para reivindicar por melhores condições dos equipamentos urbanos de consumo coletivo nestas áreas. Neste contexto, a população marginalizada é relegada do direito a cidade, tendo pouca força para questionar as políticas públicas.

Subjuga-se com esta forma das classes se distribuírem no território urbano, que a população de poder aquisitivo semelhante, especialmente as mais abastadas, se identifica com a outra de mesma classe, no ato de habitar as mesmas áreas, para juntas reclamaram por melhores condições para seu espaço habitado. Demonstrando o egoísmo existente na sociedade capitalista, já que as camadas de melhor poder aquisitivo preferem se segregarem em determinadas áreas visando melhores condições de vida, ao invés de lutarem para que estas melhorias em equipamentos urbanos de uso coletivo se distribuam homogeneamente por todo o espaço urbano e, consequentemente, para todos os habitantes das cidades. 
Retomando a análise da operação municipal realizada em Sorocaba, denominada Projeto de Desfavelamento, entende-se que as transformações do espaço urbano ocasionadas por este projeto convergiram para uma estratégia que controla os processos sociais e promove novas formas de usos e ocupação nesta área, geralmente, obedecendo aos interesses das estratégias imobiliárias que contribuem para a reprodução ampliada do capital no território.

Tal fato se solidifica em Sorocaba, pois o deslocamento das favelas que outrora se encontravam distribuídas em áreas próximas aos principais equipamentos urbanos da cidade para uma área periférica, gera a valorização imediata destas áreas que vinham sendo deterioradas devido à presença deste tipo de moradia mal acabada. Como conseqüência deste deslocamento, este local passou a apresentar grande poder de atração para novas atividades, especialmente a de serviços e habitação voltados à elite econômica, portanto, foram compatíveis com os interesses de reprodução do mercado imobiliário.

Carlos (2001, p. 28) defende que:

O processo de valorização, aliado às estratégias dos empreendedores imobiliários, reproduz um espaço cada vez mais voltado aos interesses particulares do grande capital, que, ao intervirem no urbano, interferem na prática sócioespacial e, com isso, nos modos de apropriação do espaço da vida.

Assim, como foi elucidado acima, o Projeto de Desfavelamento em Sorocaba adotou um caráter que privilegiou a reprodução dos promotores imobiliários, bem como do setor econômico, isto porque as favelas representavam barreiras para o desenvolvimento desta área com estes novos usos do solo, sendo seu deslocamento uma medida essencial para romper com esta estagnação. Em contrapartida, foi exposto que a questão social com este plano foi desconsiderada, já que os habitantes que foram envolvidos no projeto se deslocaram para áreas que se caracterizam por péssimas condições, nas quais o sentido de habitar é relegado cotidianamente. "Assim, se o Estado intervém no sentido de eliminar as barreiras ao desenvolvimento continuado do capital, não elimina as contradições do processo de reprodução espacial." (CARLOS, 2001, p. 108)

Entre as principais contradições, destaca-se na estratégia definida pela prefeitura de Sorocaba, o acréscimo do processo de segregação sócioespacial, 
gerando um espaço em que as diferentes estratificações sociais não podem ocupar as mesmas áreas, primeiramente pelo próprio modo de produção capitalista no qual as desigualdades são inerentes ao sistema, posteriormente pelo Estado que realiza projetos que fomentam estas contradições, sendo responsável pela criação de um espaço controlado, materializado pelos interesses políticos e econômicos em detrimento dos sociais.

\section{Considerações finais}

Entender a dinâmica de apropriação do espaço para moradias nas cidades é fundamental para a compreensão de outras questões sociais, já que as relações sociais se materializam no espaço urbano podendo ser visíveis sob a forma de residir da população. É assim que as contradições existentes na cidade podem ser evidenciadas pela característica da habitação, sendo que a forma de satisfazer tal necessidade indica como são realizadas as demais. Deste modo, a habitação se torna um testemunho privilegiado para a elucidação do espaço urbano. (LEFEBVRE, 1999)

Sendo assim, este artigo procurou elucidar as características e conseqüências do processo de segregação sócioespacial nas cidades, isto é, demonstrar como este fenômeno urbano afeta na dinâmica da estrutura urbana, culminando em um espaço fragmentado em que o ato de habitar determinadas áreas está totalmente associado ao lugar em que a população se situa nas classes sociais.

Evidenciando que o poder público, muitas vezes, atua na geração e fomentação deste problema urbano, relegando o direito à cidade as camadas de menor poder aquisitivo, em favorecimento exclusivo às de melhores condições econômicas. Questionando assim, as funções inerentes ao poder público que deveriam beneficiar os habitantes em geral, e não apenas parcela destes.

Foi demonstrado, então, que o Estado por meio de seus projetos, especificando o Projeto de Desfavelamento em Sorocaba, adota um conjunto de estratégias que convergem para a ampliação da segregação sócioespacial nas 
cidades, denotando um espaço de dominação no qual a população de menor poder aquisitivo é impedida de habitar as áreas que possuem as mínimas condições essenciais para a reprodução da vida. Esta política urbana promovida pelo poder público é responsável também por interferir de forma expressiva na estrutura urbana por meio de transformações nas formas e funções dos lugares, promovendo um espaço em que a classe elitizada não necessita se relacionar com as demais classes, no caso de Sorocaba representada pala população favelada, gerando assim, a assepsia do espaço. (CARLOS, 2001) Como conseqüência, predomina a existência de enormes contradições no município de Sorocaba, destacando-se a produção de lugares com inúmeros atrativos em detrimento de outros que são "esquecidos" por estas políticas públicas.

Carlos (2001, p. 15), explica que:

A ação do Estado - por intermédio do poder local - ao intervir no processo de produção da cidade reforça a hierarquia de lugares, criando novas centralidades e expulsando para a periferia os antigos habitantes, criando um espaço de dominação. Com isso, impõe sua presença em todos os lugares, agora sob controle e vigilância (seja direta ou indireta).

Foi demonstrado, também, que a distribuição das classes sociais no território urbano segue a lógica de manutenção de privilégios por parte da população mais abastada, já que as reais intenções desta classe, em apropriar-se de espaços próximos, estão totalmente vinculadas à possibilidade de reivindicar por melhores condições quanto aos equipamentos urbanos de uso coletivo frente ao poder público.

Assim, procurou-se examinar a situação da estrutura urbana em Sorocaba a partir de uma política pública, que se caracterizou por manter um caráter segregador de apropriação do espaço, sendo que as transformações nas formas e funções da cidade, isto é, a transferência das favelas pelo território ocasionou um direcionamento das melhores áreas de cidade com relação à infraestrutura e serviços para o uso, quase que exclusivo, por parte da população que detém bons recursos financeiros. Em contrapartida, destinou as camadas de menor respaldo financeiro áreas impróprias para a realização da vida. 
Tal projeto realizado em Sorocaba, portanto, foi compatível com a reprodução do espaço urbano em função das estratégias imobiliárias, sendo responsável por limitar as condições, assim como as possibilidades de seu uso.

\section{Referências}

CARLOS, A. F. A. Espaço-tempo na metrópole: a fragmentação da vida cotidiana. São Paulo: Contexto, 2001.

2004.

O espaço urbano: novos escritos sobre a cidade. São Paulo: Contexto,

CORRÊA, R. L. Trajetórias Geográficas. Rio de Janeiro: Bertrand Brasil, 2001.

ENGELS, F. A situação da classe trabalhadora em Inglaterra. Tradução de Conceição Jardim e Eduardo Lúcio Nogueira. Coleção SíNTESE. Livraria Martins Fontes. Editorial Presença, 1975.

HARVEY, D. A justiça social e a cidade. São Paulo. Hucitec, 1980.

INSTITUTO BRASILEIRO DE GEOGRAFIA E ESTATÍSTICA - IBGE (2000). Censo Demográfico, 2000.

KOWARICK, L. A espoliação urbana. Rio de Janeiro: Paz e Terra, 1983.

LEFEBVRE, H, - 1905 - A cidade do capital. Tradução de Maria Helena Rauta Ramos e Marilene Jamur. Rio de Janeiro: DP \& A, 1999.

2001

O direito à cidade. Tradução: Rubens Eduardo Frias. São Paulo: Centauro,

MARICATO, E. Brasil, cidades: alternativas para crise urbana. Petrópolis: Vozes, 2002.

MEIRA, S. I. Planejamento e Gestão Urbanos em Sorocaba-SP: análise das políticas públicas de habitação popular. 2005. 147 f. Dissertação (Mestrado em Geografia) - Universidade Federal do Paraná, Curitiba, 2005.

Planejamento e Gestão Urbanos em Sorocaba-SP: análise das políticas públicas de habitação popular. R. RA'E GA, Curitiba, n. 12, p. 59-72, 2006. Editora UFPR. 
RODRIGUES, A. M. Na procura do lugar o encontro da identidade - Um estudo do processo de ocupação de terras: Osasco. $333 \mathrm{f}$. Tese (Doutorado) Faculdade de Filosofia, Letras e Ciências Humanas - Departamento de Geografia da Universidade de São Paulo. São Paulo, 1988.

SINGER, P. O uso do solo urbano na economia capitalista. In: MARICATO, E. (org.). A produção capitalista da casa (e da cidade) no Brasil industrial. São Paulo: Alfa-Omega, 1982.

SANTOS, M. A urbanização brasileira. São Paulo: Hucitec, 1994.

VILLAÇA, F. Espaço intra-urbano no Brasil. São Paulo: Studio Nobel: FAPESP: Lincoln Institute, 2001. 